\title{
Ontogenetic development of the gastrointestinal tract of African lungfish larvae Protopterus aethiopicus (Heckel 1851): A light microscopy study
}

\author{
Martin Sserwadda, ${ }^{1,2}$ | Nancy Nevejan ${ }^{1}$ | Ronald Ntanzi ${ }^{1}$ | Pieter Cornillie ${ }^{3}$ | \\ Wim Van den Broeck ${ }^{3}$ | Gilbert Van Stappen ${ }^{1}$
}

${ }^{1}$ Laboratory of Aquaculture \& Artemia Reference Center, Ghent University, Gent, Belgium

${ }^{2}$ Department of Agriculture and Environmental Sciences, Mountains of the Moon University, Fort Portal, Uganda

${ }^{3}$ Department of Morphology, Faculty of Veterinary Medicine, Ghent University, Merelbeke, Belgium

\section{Correspondence}

Laboratory of Aquaculture \& Artemia Reference Center, Ghent University, Coupure Links 653, B-9000 Gent, Belgium. Emails: Martin.Sserwadda@ugent.be; martinsserwadda5@gmail.com

Funding information

VLIR-UOS, programme ZIUS, 2013-2024, AP027

\begin{abstract}
The organogenesis of the digestive system was described in the African lungfish (Protopterus aethiopicus) from 6 days post-hatching (6 DPH) to 17 days post-hatching (17 $\mathrm{DPH}$ ) reared at $27^{\circ} \mathrm{C}$. To elucidate the position of the gastrointestinal tract in relation to the neural tube, notochord and yolk sac at $6 \mathrm{DPH}$, and to the vertebral column, lungs and kidneys at $17 \mathrm{DPH}$, larvae were mapped by means of computer-assisted 3D reconstructions starting from histological serial sections. The larvae showed a simple digestive tract, which appeared as a straight undifferentiated and closed tube at $6 \mathrm{DPH}$. Microscopical observation showed that yolk reserves were not completely depleted by $17 \mathrm{DPH}$. During the endogenous feeding period at least up to $17 \mathrm{DPH}$, the larval digestive system experienced a fast transformation with almost complete development of most digestive organs (pharyngeal teeth, intestinal vestibule, intestine and liver). Our findings suggest that, by $17 \mathrm{DPH}$, African lungfish larvae are ready to start exogenous feeding.
\end{abstract}

\section{KEYWORDS}

exogenous feeding, intestinal vestibule, organogenesis, spiral valve

\section{1 | INTRODUCTION}

Lungfish are air-breathing fish endemic to Africa (Protopterus), South America (Lepidosiren) and Australia (Neoceratodus) (Icardo, Wong, Colvee, Loong, \& Yuen, 2010). African lungfish represent the family Protopteridae (Mlewa, Green, \& Dunbrack, 2010) with four species in the genus Protopterus. Lungfish is in great demand amongst the consumers, due to its substantial fillet size and good taste (Walakira, Atukunda, Molnar, \& Veverica, 2012). With the rapid increase in demand, attempts have been made to culture the African lungfish Protopterus aethiopicus and other species, and the effect of formulated feeds on wild juveniles has been investigated (Walakira, Molnar, Phelps, \& Terhune, 2014).
Many studies were carried out to focus on the organization of the alimentary tract (Icardo et al., 2011; Joss \& Hassanpour, 2009; Rafn \& Wingstrand, 1981), highlighting the absence of a true stomach (Kardong, 2006) and studying the anatomy and histology of the spiral valve intestine (Icardo et al., 2011; Joss \& Hassanpour, 2009).

The development of an efficient digestive system is reflected in the anatomy of the gastrointestinal tract (GIT), accessory digestive organs and in the production of digestive enzymes (Onura, Van Den Broeck, Nevejan, Muendo, \& Van Stappen, 2018). In teleosts, the ontogenetical development of the gastrointestinal tract is similar and is initiated by endogenous feeding at hatching (Govoni, Boehlert, \& Watanabe, 1986; Grosell, Farrell, \& Brauner, 2010; 
Wilson \& Castro, 2010). However, there are differences between species in the presence or rate of stomach development, the shape of the gut, intestinal differentiation and functionality, which reflect differences in trophic levels (Khojasteh, 2012; Onura et al., 2018). Thus, understanding the progressive changes in the gastrointestinal tract of fish larvae is important in defining a proper larval feeding and weaning strategy (Gisbert, Ortiz-Delgado, \& Sarasquete, 2008; Onura et al., 2018; Osman, Wuertz, Mekkawy, Verreth, \& Kirschbaum, 2008). Several authors have stated how the complexity of the intestinal morphology in teleost fish varies with age and is also influenced by the quantity and quality of the feed (Gisbert, Conklin, \& Piedrahita, 2004; Giesbert et al., 2008; Onura et al., 2018; Rønnestad et al., 2013). The gastrointestinal tract and associated organs are some of the most metabolically active tissues in an animal. Therefore, in periods of food shortage or poor food quality, an animal may reduce the size and function of their GIT to conserve energy (German, Neuberger, Callahan, Lizardo, \& Evans, 2009). Starvation or poor feed quality also resulted in a decreased size of the gut with reduced cell functions in Pterygoplichthys disjunctivus (German et al., 2009). Feeding Artemia nauplii in combination or not with dry feed resulted into significant higher goblet cell counts in all intestinal parts of African catfish Clarias gariepinus larvae (Onura et al., 2018). As such, this knowledge is crucial for the successful introduction of any species into aquaculture.

Histology is an appropriate tool to analyse the development of the gastrointestinal tract: the determination of the time points at which the GIT is differentiated can be assessed, based on which feeding regimes can be optimized. One of the first steps to enhance the success of $P$. aethiopicus larviculture is the description of the ontogeny of the digestive system in order to synchronize the larval stage of development and maturation of the digestive organs with the feeding protocol and rearing practices, as well as to identify limiting factors during larval rearing. Thus, the histological development of the digestive tract has been regularly used as a biomarker to assess the nutritional status of fish at early stages of development (Gisbert, Morais, \& Moyano, 2013; Gisbert et al., 2008, 2014).

The objective of this study was to investigate the ontogenetic development of the gastrointestinal tract of $P$. aethiopicus larvae from 6 days post-hatching (DPH) up to $17 \mathrm{DPH}$. Light microscopy was used to identify the development of the gastrointestinal tract at different time points. The $3 \mathrm{D}$ reconstruction technique was used to identify the different anatomical structures at $6 \mathrm{DPH}$, since it was difficult at the beginning to clearly identify the gastrointestinal tract as it was a closed tube, and at $17 \mathrm{DPH}$ to assess readiness of the GIT for exogenous feeding. These developmental stages in terms of days post-hatching were chosen to generate knowledge about the differentiation of the digestive tract of African lungfish during ontogenetic development. This is essential for understanding the nutritional physiology of larval lungfish and synchronization of the physiological stage of development with feeding practices and rearing protocols. To our knowledge, this is the first histological study on the ontogenetic development of African lungfish larvae. This new information is expected to provide fundamental knowledge for future nutritional studies during larval rearing of this lungfish species.

\section{2 | MATERIALS AND METHODS}

\section{1 | Experimental setup}

The larval rearing trials took place at the Aquaculture Research and Development Centre (ARDC), Kajjansi, Uganda, in a static system comprising of nine glass aquaria of $60 \mathrm{~L}$ each, set at a rearing temperature of $27 \pm 1^{\circ} \mathrm{C}$. The temperature was maintained by inserting a thermostatic heating rod in each aquarium. Aeration in each aquarium was provided by a single air stone. The aquaria were cleaned twice a day (morning and evening) by siphoning with a small tube that could suck up dead larvae, and water was replaced completely every morning. Borehole water and a natural photoperiod of $12 \mathrm{~L} / 12 \mathrm{D}$ was used. Fluorescent tubes in the hatchery of about 1,000 lux were used as the light source. Experimental parameters such as temperature and stocking density were chosen based on previous experiments carried out by the National Fisheries Resources Research Institute (unpublished data).

\subsection{Collection and hatching of eggs}

Permission was sought and got from Dr. Rukunya. E., at the Directorate of Fisheries Resources, Ministry of Agriculture, Animal Industry and Fisheries, Entebbe, Uganda, to collect and use wild fish eggs.

A total of 16 egg nests were collected from Lake Bisina $\left(1^{\circ} 36^{\prime} 28^{\prime \prime} \mathrm{N} 33^{\circ} 57^{\prime} 43^{\prime \prime} \mathrm{E}\right)$, eastern Uganda and transported (transit time 4 to $5 \mathrm{hr}$ ) in a well-aerated water tank to ARDC. On reaching the hatchery, the eggs were disinfected using an $8 \mathrm{gL}^{-}$ ${ }^{1}$ sodium chloride $(\mathrm{NaCl})$ bath for 2 min ( $\mathrm{NaFIRRI-unpublished}$ data). This was done as a preventive measure to avoid fungal infection. After disinfection, the eggs were spread out onto hatching trays and incubated at $27 \pm 1^{\circ} \mathrm{C}$. The hatched larvae were counted individually, and 900 larvae were pooled together in one separate glass stocking aquarium filled up to the $30-\mathrm{L}$ mark until $6 \mathrm{DPH}$. On the morning of $6 \mathrm{DPH}$, each of the nine glass aquaria was randomly stocked at 3 larvae $L^{-1}$ and was filled up to the 33-L mark. In the absence of published data about the mouth size of African lungfish larvae and given the wide use of Artemia as a starter feed, our larvae were provided with what was regarded as possible suitable starter feeds, comprising of a commercial dry feed, freshly hatched Artemia nauplii and decapsulated Artemia cysts of Great Salt Lake-type Artemia franciscana Kellogg 1906 (Ocean Nutrition). One of the three possibly suitable starter food types above was administered to a set of three aquaria until the end of the rearing period at $17 \mathrm{DPH}$. Feeding was done starting at 9:00 a.m., 12:00 and 4:00 p.m. every day. The live Artemia nauplii were maintained alive by storing them under refrigeration at $4^{\circ} \mathrm{C}$. 


\section{3 | Sampling procedure and} morphological analysis

\subsection{1 | Fixation, tissue processing and sectioning}

Histological sections were used for describing the development of the gastrointestinal tract of the lungfish larvae. At least nine live fish larvae per feeding treatment (three larvae per replicate) were randomly sampled on 6, 10 and $17 \mathrm{DPH}$. The larvae were fixed in Bouin's solution (saturated aqueous picric acid, formaldehyde $37 \%$, acetic acid [glacial]) until processing and transported to the Department of Morphology, Faculty of Veterinary Medicine, Ghent University, Merelbeke, Belgium. On processing, the larvae were dehydrated in graded alcohols and embedded in paraffin wax using the STP 120 Microm Tissue Processor and the embedding centre EC350-1 and 2 (Microm, Prosan), respectively, as described by Gurcan et al. (2009). For light microscopic observation, transverse sections of $8 \mu \mathrm{m}$ thickness were cut with the HM 360 Microtome using the Section Transfer System (Microm, Prosan). For general histology, the sections were stained with haematoxylin/eosin (HE) and periodic acidSchiff (PAS) following the description in Fischer, Jacobson, Rose, \& Zeller, 2008.

\subsection{2 | Morphological analysis}

Morphological analysis was performed using the Olympus BX61 light microscope equipped with an Olympus DP73 camera. Epithelial classification was based on the number of cell layers and the shape of the most apical epithelial cells.

\section{D Reconstruction}

The quality of a variable number of slices of both 6 and $17 \mathrm{DPH}$ larvae was assessed using an Olympus BX53 light microscope. All the selected slices for reconstruction were photographed with an Olympus DP73 digital camera mounted on the microscope with a $4 \mathrm{X}$ magnifying objective lens. All images were saved in jpeg format in one folder containing 1,315 Amira stacked slices. The 3D reconstruction image was made following the description of Cornillie, Van Den Broeck, and Simoens, (2008).

\section{3 | RESULTS}

\section{1 | Visual observation of eggs and larvae}

The eggs were oval, about $3 \mathrm{~mm}$ in diameter and varied in colour as some were orange, creamy, green or white. It was later observed that white eggs were non-viable. Hatching was achieved 3 days after arrival in the hatchery. On hatching, the larvae appeared coiled and creamy in colour. The newly hatched larvae were immotile and settled on the bottom of the tank. They had a relatively large yolk sac and an eyespot and had a total length of about $1.2 \mathrm{~cm}$. The fish larvae grew from a mean wet weight of $0.05 \pm 0.02 \mathrm{~g}$ to $0.08 \pm 0.02 \mathrm{~g}$. By $17 \mathrm{DPH}$, the animals still did not eat in contrast to what we had anticipated, although anatomically the GIT seemed ready for exogenous feeding. Consequently, all the histological work in this paper refers to larvae within the endogenous feeding phase.

\section{2 | 3D Reconstruction}

The internal morphology of the lungfish at both 6 and 17 DPH was well conserved, and therefore, no substantial difficulties were encountered during slice alignment and 3D reconstruction (Figure 1a $\& b)$. The position of the gastrointestinal tract observed in the cross sections of the 6 and $17 \mathrm{DPH}$ lungfish larvae in the 3D reconstruction was comparable to the reference 6 and 17 DPH slices, respectively, and was in similar orientation relative to the notochord, neural tube and yolk sac for the $6 \mathrm{DPH}$ larvae and to the vertebral column, lungs and kidneys for the 17 DPH larvae.

\subsection{Histological development of the digestive system in the endogenous feeding stage}

The development of the gastrointestinal tract and the major differences at the different time points are summarized in Table 1 below.

\subsection{1 | Yolk sac}

On hatching, the larvae had a large yolk sac. The digestive tract of the larvae consisted of a straight tube lying dorsal to the large eosinophilic yolk sac (Figure 1a). The yolk extended on the ventral side from the head region all the way to the caudal region of the larvae. Most of the yolk reserves were consumed between 6 and $10 \mathrm{DPH}$. At $17 \mathrm{DPH}$, the yolk sac was still visible in histological sections. The yolk sac was surrounded by a thin undifferentiated eosinophilic epithelial layer consisting of 2 to 3 cell layers. The yolk consisted of a large accumulation of ovoid eosinophilic yolk particles with scattered spherical non-stained vacuoles throughout the yolk sac matrix. These vacuoles corresponded to lipids that were washed out during the paraffin embedding process of the samples.

\subsection{2 | Mouth, oral cavity and pharynx}

By $6 \mathrm{DPH}$, the mouth and anal opening appeared closed (Table 1). The larvae generally stayed at the bottom of the aquaria attached to the base by a thoracic sucker until swim up, a period when larvae start to move about, either to pick up air to inflate the swim bladder or to look for food. The buccal cavity lumen was still closed (Figure 2a). The histological structure of the gastrointestinal tract is not yet differentiated at this stage (Figure $2 a-c$ ). 
FIGURE 1 (a) Lateral view of selected internal organs of 3D reconstructed image of 6 DPH P. aethiopicus larva, showing the 1a-neural tube, 1b-notochord, 2-an undifferentiated digestive tube, 3-yolk sac (reconstruction with Amira software). Each box is $500 \mu \mathrm{m}$ in $\mathrm{X}$ and $\mathrm{Y}$ direction. (b) Lateral view of selected internal organs of 3D reconstructed image of $17 \mathrm{DPH}$ P. aethiopicus larva, showing the 1-buccal cavity, 2-pharynx, 3-vestibule, 4-spiral valve intestine, 5-cloaca, 6-liver, 7-pancreas, 8-lungs, 9-kidneys and 10-vertebral column (reconstruction with Amira software). Each box is $500 \mu \mathrm{m}$ in $X$ and $Y$ direction



(a)

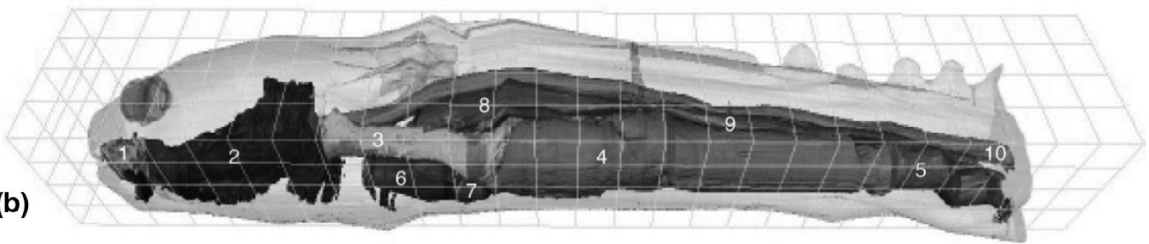

TAB LE 1 Development of the gastrointestinal tract of $P$. aethiopicus larvae from $6 \mathrm{DPH}$ to $17 \mathrm{DPH}$

\begin{tabular}{lllll}
\hline Organ & Structure & 6 DPH & 10 DPH & 17 DPH \\
\hline Oral cavity & Mouth & Closed & Closed & Open \\
\hline Buccopharyngeal cavity & Buccopharynx & Closed & Closed & Open \\
\hline Buccopharyngeal cavity & Teeth & Absent & $\begin{array}{l}\text { Teeth buds present in } \\
\text { underlying tissue }\end{array}$ & $\begin{array}{c}\text { Teeth erupting into the lumen of } \\
\text { the buccopharyngeal cavity }\end{array}$ \\
\hline Vestibule & Vestibule & Absent & Present & Present \\
\hline Spiral valve & Intestinal tract opening & Closed & Partially opened & Fully opened \\
& Spiral coils & Absent & Absent & One complete spiral coil \\
\hline Hind gut & Cloaca & Absent & Absent & Present \\
\hline Digestive cells & Goblet cells & Absent & Absent & Present \\
\hline & Enterocytes & Absent & Present & Present
\end{tabular}

By $10 \mathrm{DPH}$, the lumen of the buccal cavity was open (Table 1). The buccopharyngeal cavity was lined by a layer of undifferentiated epithelium consisting of 2 cell layers and beneath it a thin layer of submucosa surrounded by a thick layer of connective tissue rich in collagen by day 10 post-hatching. The basal layer was mainly composed of columnar cells while the top layer had mainly cuboidal cells. These cells had basal nuclei. This epithelium was actively growing as evidenced by several cells undergoing mitosis. External taste buds were present by this time, and the presence of pigment cells was also noticed (Figure 3a). Teeth development was seen in the connective tissue underlying the buccopharyngeal epithelium (Figure $3 b$ ).

By $17 \mathrm{DPH}$, the epithelium of the buccopharyngeal cavity was composed of a double layer of cells evolving into a stratified epithelium. The basal layer was mainly composed of columnar cells, while the top layer had cuboidal cells. These cells had basal nuclei. The epithelium was actively growing as evidenced by several cells undergoing mitosis. The epithelium also contained several goblet cells protruding into the lumen (Figure 4a). These secretory cells stained purple with PAS staining, indicating the presence of neutral goblet cells in the buccopharyngeal cavity. The lungfish larvae had both external and internal taste buds developed along the skin of the mouth and internal taste buds along the epithelium of the buccopharyngeal cavity, especially at its upper side (Table 1). The teeth plates seen at $10 \mathrm{DPH}$ had developed further and were seen piercing through the epithelial layer erupting into the lumen of the buccopharyngeal cavity by $17 \mathrm{DPH}$ (Figure 4b). 

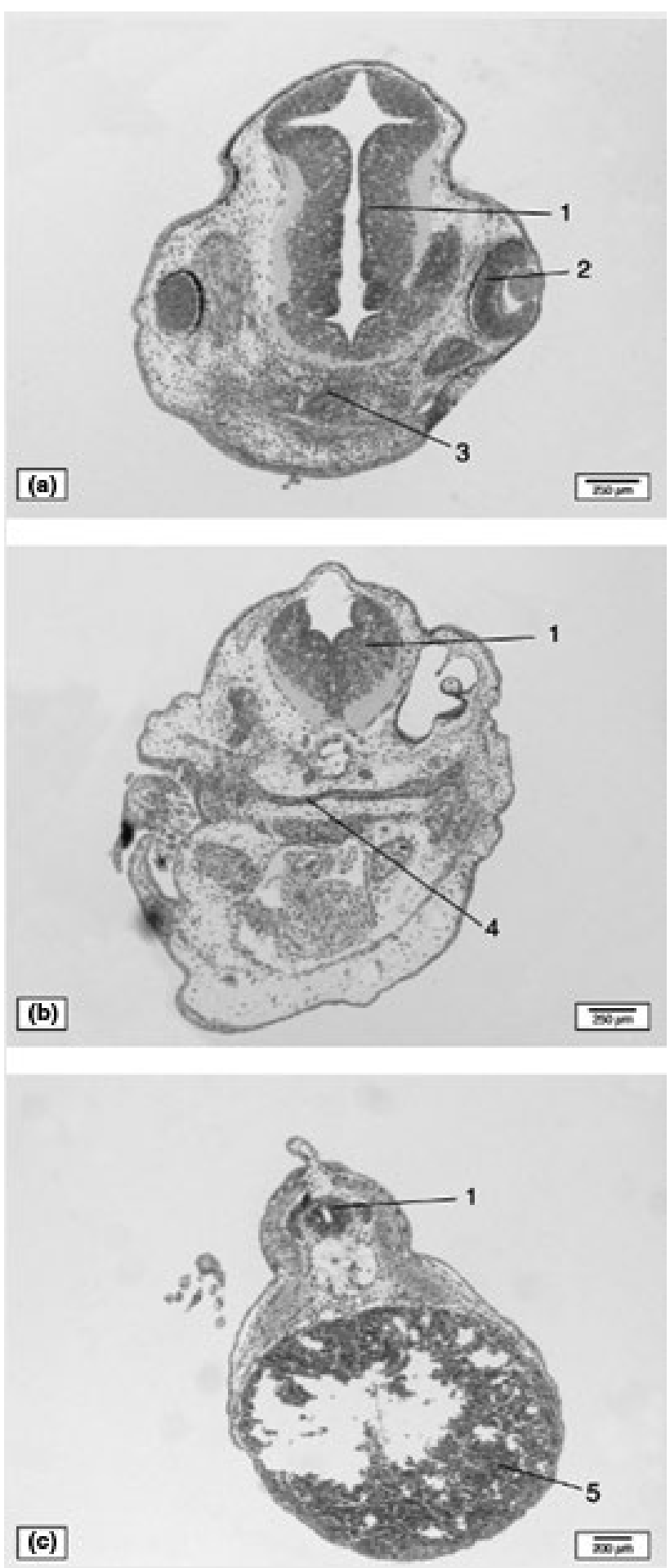

FIGURE 2 Cross section of $P$. aethiopicus lungfish larvae at $6 \mathrm{DPH}$ at different levels. 2a: at the level of the eyes; future buccal cavity (1), $2 \mathrm{~b}$ : at the beginning of the dorsal fin; closed gastrointestinal tract (2); 2c: at the level of the yolk sac; yolk (3) Stain: haematoxylin/eosin (HE)

\subsection{3 | Intestinal vestibule}

By $6 \mathrm{DPH}$, the digestive tract appeared as a straight undifferentiated tube lying dorsal to the yolk sac but below the notochord and neural
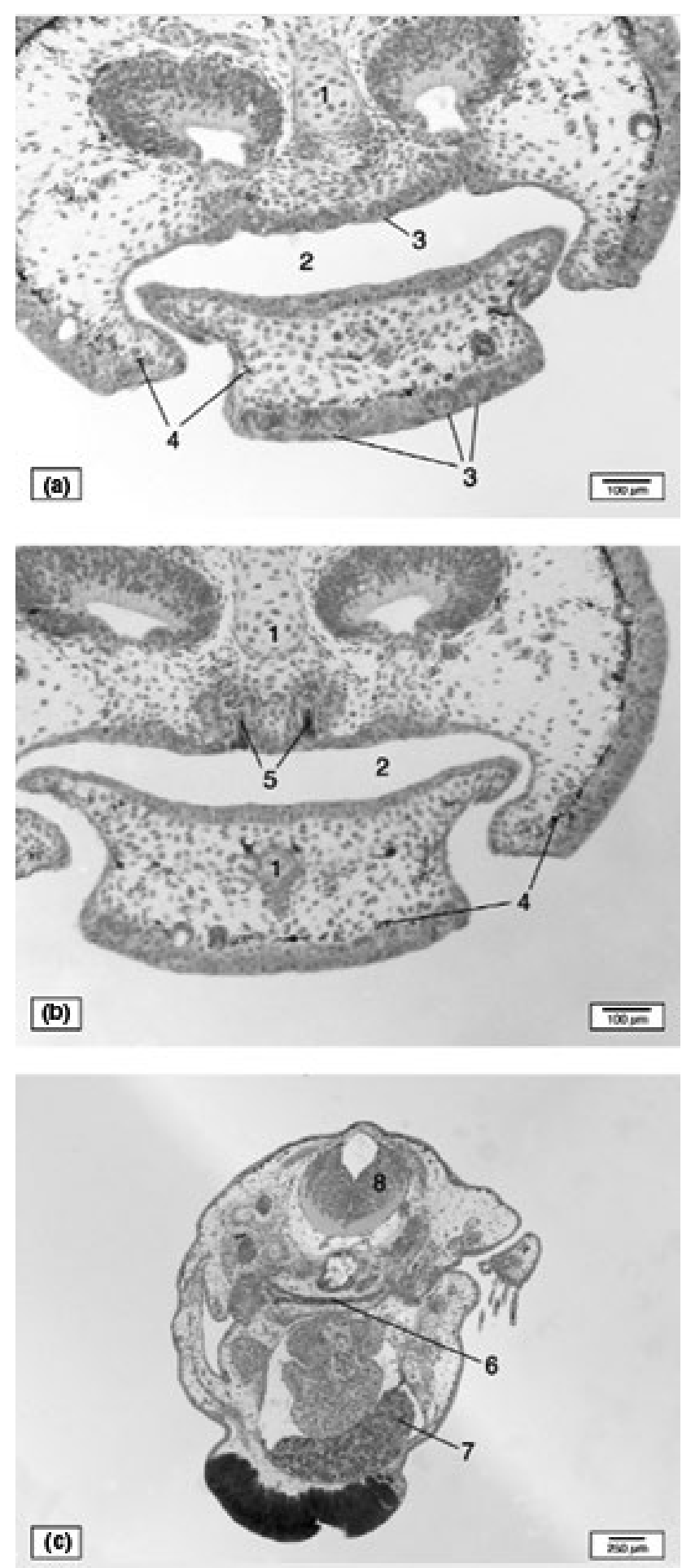

FIGURE 3 Cross section of $P$. aethiopicus lungfish larvae at 10 $\mathrm{DPH}$ at different levels. $3 \mathrm{a}$ and $3 \mathrm{~b}$ : at the level of the buccal cavity; cartilage (1), lumen of buccal cavity (2), taste buds (3), pigment cells (4) and tooth plates (5); 3c: at the level of the dorsal fin; partially opened gastrointestinal tract (6) and yolk (7)

tube (Figure 1a). By $10 \mathrm{DPH}$, the digestive tract had differentiated into a buccal cavity, intestinal vestibule and spiral valve intestine. The intestinal vestibule was located directly posterior to the buccopharynx and extended from the posterior end of the gills to the spiral valve 

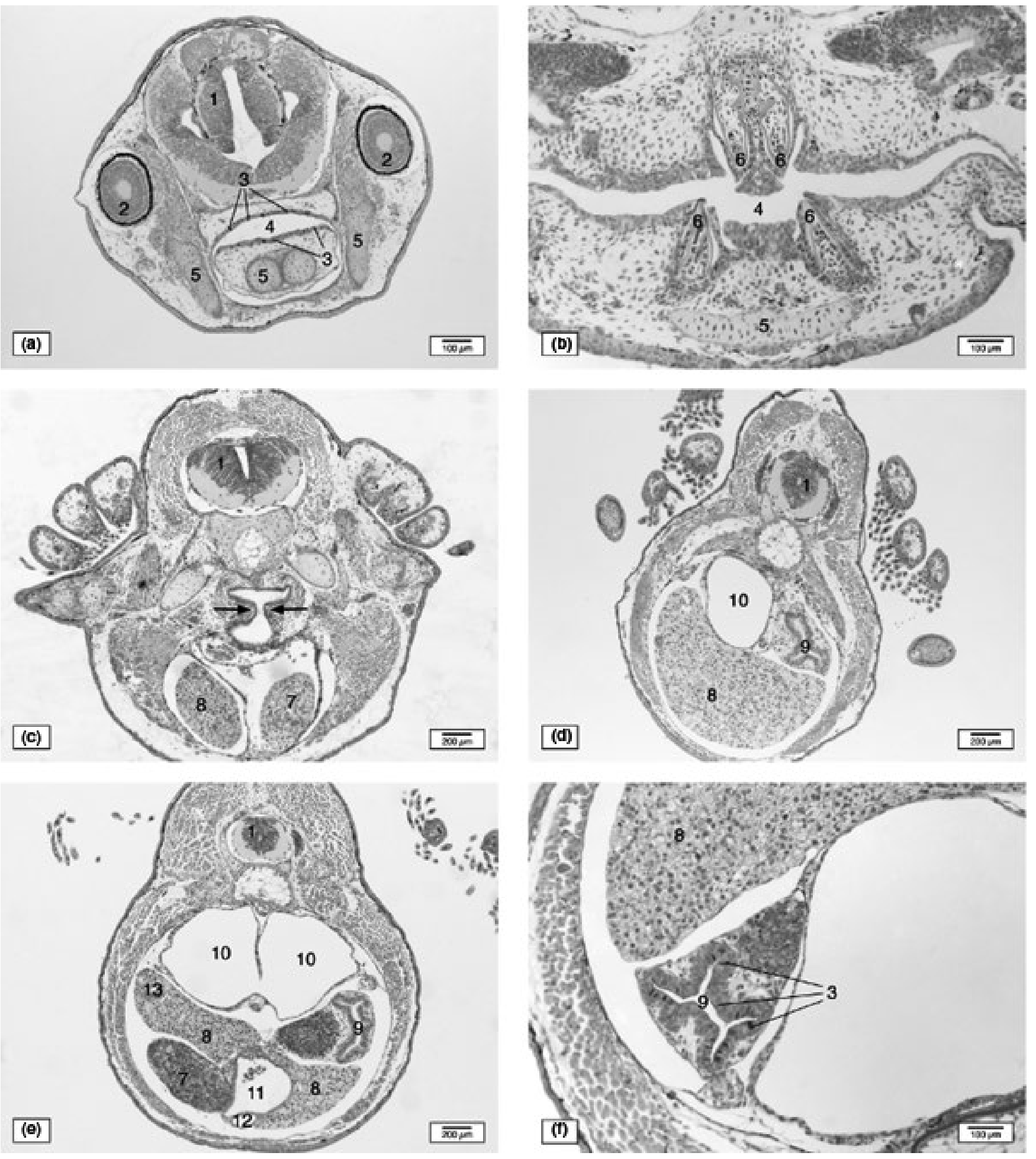

FIGURE 4 Cross section of 17 DPH P. aethiopicus lungfish larvae at different levels. 4a: at the level of the eyes; goblet cells (1), 4b: at the level of the buccal cavity; teeth (4), $4 \mathrm{c}$ and $4 \mathrm{~d}$ : at the beginning of the dorsal fin; constriction of the gastrointestinal tract (arrows), gastrointestinal tract (7), respiratory tissue (8) and liver (6), 4e: constriction giving rise to two lobes of the lung (8), gall bladder (9) and bile duct (10), 4f: showing the liver (6) and gastrointestinal tract (7) on one side with the respiratory tissue on the other side

intestine. The wall of the intestinal vestibule at $10 \mathrm{DPH}$ consisted of a multilayered epithelium surrounded with a thin submucosa with a very dense connective tissue that was rich in collagen. The multilayered epithelium consisted of at least 2 cell layers of columnar to cuboidal cells with basal and apical nuclei. There was also a ridge developing in the intestinal vestibule whose epithelium appeared undifferentiated by $10 \mathrm{DPH}$.

By $17 \mathrm{DPH}$, the epithelium of the vestibule was mainly composed of columnar to cuboidal epithelial cells that appeared to be organized in at least two cell layers. This was evidenced by the presence of several 
basal and apical nuclei scattered within the epithelium. It also had some goblet cells interspaced between the epithelial cells. The goblet cells contained PAS-positive material which was also seen covering the epithelial lining into the lumen (Figure 4a). The epithelium also had cells actively undergoing mitosis. The epithelium was surrounded by adipose tissue with some blood vasculature and lymphatic ducts together with collagen. There also seemed to be condensation of mesenchymal tissue which signals muscle tissue formation by $17 \mathrm{DPH}$. The posterior end of the intestinal vestibule appeared to be folded, with folds increasing towards the start of the spiral valve intestine by $17 \mathrm{DPH}$.

\subsubsection{Spiral valve intestine}

At $6 \mathrm{DPH}$, the spiral valve intestine was undifferentiated as a straight tube lying dorsal to the yolk sac (Figure 1a). The spiral valve intestinal epithelium at $10 \mathrm{DPH}$ was mainly composed of two cell layers of epithelial cells. These epithelial cells were mainly cuboidal to elongate in shape evidenced by both basal and apical nuclei scattered throughout the epithelium. The lumen of the spiral valve intestine was partially closed, and there was no cloaca by this stage of development (Figure 3c).

At the beginning of the spiral intestine, the epithelial lining was made up of a single layer of flattened cells at $17 \mathrm{DPH}$, caudally transforming into an epithelium with two cell layers. These cells were mainly cuboidal in shape. The epithelium contained goblet cells interspaced between the epithelial cells. There was the presence of cells undergoing mitosis. Towards the end of the spiral intestine at $17 \mathrm{DPH}$, the gut lumen was seen to constrict laterally to give rise to two tubular structures, the respiratory tract and cloaca (Figure 4c). The intestine stayed dorsal but turned laterally to the right and continued as the cloaca while the bigger tubular organ further constricted and divided into the two lobes of the lungs (Figure 4e). PASstained sections allowed identification of two epithelial cell types based on their staining properties: enterocytes and goblet cells. Enterocytes were the dominant cells, and they showed a pale to moderately stained cytoplasm, whereas goblet cells presented an intensely stained cytoplasm. Variable amounts of pigment cells were also observed. At $17 \mathrm{DPH}$, the digestive tract was fully developed, and the spiral intestine leads into a cloaca which was the final segment of the gut. The cloaca was lined by columnar cells arranged in two layers with goblet cells interspaced between them. Several small folds appeared in both the spiral valve intestine and in the cloaca by $17 \mathrm{DPH}$ (Figure 4f). By $17 \mathrm{DPH}$, only one turn of the spiral valve was observed (Figure 5 ).

\subsection{5 | Liver}

At $17 \mathrm{DPH}$, the liver was fully differentiated with a well-developed gall bladder and bile duct (Figure 4e). The gall bladder had some luminal content (Figure 4e). The mucosa of the gall bladder had some small folds and a cuboidal epithelium. The hepatocytes revealed discrete cell margins with large round centrally located nuclei (Figure 4f).

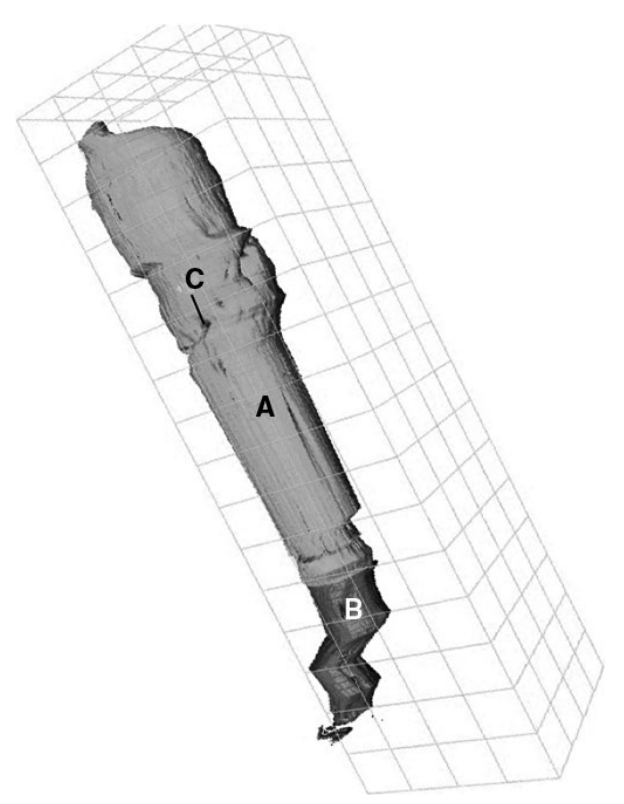

FIGURE 5 Three-dimensional images showing a lungfish spiral valve (A), cloaca (B) and the only spiral turn (C) at $17 \mathrm{DPH}$

The nuclei of the hepatocytes had dark chromatin granules. There was clear evidence of fat deposition by this stage, and some hepatocytes had some eosinophilic granules (Figure $4 d$ ). The liver cells were clearly attached to each other, making it difficult to identify whether there was any connective tissue between the cells. The liver vasculature was also well developed by $17 \mathrm{DPH}$ (Figure 4d).

\section{4 | DISCUSSION}

This is the first study to show the development of the digestive organs in African lungfish as 3D model. The 3D reconstruction model enables us to understand the morphology of the digestive organs and also provides a deeper insight into the mechanisms of feeding and digestive physiology during ontogeny (Kamisaka and Rønnestad, 2011). This morphological assessment is critical in evaluating the changes in the gastrointestinal tract development and also the larvae's ability to utilize food (Santos, Pedreira, Santos, \& Souza, 2016). Morphology and spatial organization of the gastrointestinal tract can be a challenge to understand on the basis of 2D histological sections or drawings, especially when the elongated gut gets more coiled in the peritoneal cavity as the larvae develops (Kamisaka and Rønnestad, 2011).

Some authors have stated that the alimentary canal in fish develops from endodermal cells located just above the yolk sac. At hatching, the alimentary canal is just a straight tube lying dorsal to the yolk sac, is closed at the mouth and anus in some species and is histologically undifferentiated along its length (Govoni et al., 1986; Zambonino Infante et al., 2008). Our findings at 6 DPH agree with Govoni et al. (1986) and Zambonino et al. (2008) since in the marbled African lungfish larvae, the digestive tract was a straight tube of undifferentiated cells lying dorsal to the yolk sac. 
In African lungfish, the mouth and buccal cavity opening occurred between 10 and $11 \mathrm{DPH}$. This is rather a slow development as compared to African catfish (Clarais gariepinus) and butter catfish (Ompok bimaculatus) larvae, in which mouth and buccal cavity open between 1 and 2 DPH (Pradhan, Jena, Mitra, Sood, \& Gisbert, 2012; Verreth, Torrelle, Spazier, \& Sluiszen, 1992). Catfish species are amongst the most studied freshwater fish species, and in these species, there is a mixed feeding phase during which an overlap of endogenous and exogenous feeding occurs. The mixed feeding phase usually affects growth, survival and larval development through neutralizing any potential deficit in nutrient provision prior to depletion of yolk reserves during the time of transition to exclusively exogenous feeding (Pradhan et al., 2012; Treviño et al., 2011). The transition to exogenous food in the presence of yolk reserves signifies the functionality of the alimentary canal, although further structural and functional development still continues from the larval to the juvenile and adult stages (Jaeroszewska \& Dabrowski, 2011).

In our larvae, during the endogenous feeding period, the digestive system experienced fast transformation with the almost complete development and differentiation of all digestive organs between 6 and $17 \mathrm{DPH}$. This agrees with other studies (Buddington, 1985; Govoni et al., 1986; Ostaszewska, 2005), who also showed that absorption of the yolk sac is accompanied by intense development of the digestive system in bony fish. The endogenous feeding in marbled African lungfish larvae reared at $27^{\circ} \mathrm{C}$, took place for almost 2 weeks as macroscopic yolk resorption was achieved by $14 \mathrm{DPH}$. However, traces of yolk granules were still visible microscopically even at $17 \mathrm{DPH}$. From our observations at $17 \mathrm{DPH}$, African lungfish larvae seem ready for food digestion anatomically, although they still or hardly take up any exogenous feed, and primarily still rely on yolk. It is therefore worthwhile to investigate whether cofeeding of the yolk sac larvae with exogenous food is possible in the larviculture of this fish.

The timing of the development of teeth, taste buds and goblet cells by $10 \mathrm{DPH}$, in the buccal pharyngeal cavity and vestibule in the African lungfish larvae, coincided with the opening of the buccopharyngeal cavity. The presence of both external and internal taste buds together with the increased the presence of goblet cells and the eruption of teeth into the lumen of the buccal pharyngeal cavity by $17 \mathrm{DPH}$ coincided with the onset of exogenous feeding, which might be attributed to the involvement of the above structures in capture, taste and swallowing of preys. African lungfish generally prey on mollusks, small fish, crustaceans, aquatic insects and worms (Mlewa et al., 2010). Thus, the abundance of goblet cells in the buccal pharyngeal cavity and vestibule and their secretions, rich in PAS-positive mucosubstances, might serve as a lubricant in protecting both the buccopharyngeal and vestibule mucosa from the abrasion that ingesting these preys could produce (Gisbert, Sarasquete, Williot, \& Castelló, 1999). By 17 DPH, the vestibule had an epithelium with a variable number of layers and a longitudinal ridge, but no glands were observed and indeed not a true stomach. Our findings on this section agree with Icardo et al. (2011), who also found that juvenile West African lungfish had no true stomach. The vestibule may simply function as a food storage organ or is meant to slow down the transit of food (Icardo et al., 2010, 2011). In addition to the above-mentioned role as a lubricant, the goblet cell secretions could participate in the digestion of food and its transformation into chyme and in the absorption of easily digested substances (Sarasquete, Gisbert, Ribeiro, \& Dinis, 2001).

The presence of a spiral intestine is a primitive feature usually described in sturgeons and in some elasmobranches (Icardo et al., 2010; Kardong, 2006). This anatomical development simply increases the food transit time and facilitates digestion and absorption (Holmgren \& Nilsson, 1999; Icardo et al., 2010). The general organization of the spiral valve intestine appears to be similar in life stages of the African lungfish species. It is only the number of the coils that appears to increase with age, as the highest number of coils observed in a single section of West African lungfish was two coils, with the Australian lungfish having the highest number, that is six coils (Icardo et al., 2010; Rafn \& Wingstrand, 1981). Only one coil was observed at 17 DPH in our study, due to the age of the specimen used. A higher number of coils indicates a delayed digestion time (Icardo et al., 2010). The spiral valve intestine contained a smooth intestinal surface by $17 \mathrm{DPH}$. This is different from what is present in both 3- to 4-year-old juvenile Australian and West African lungfish, where the spiral valve is clearly divided into two well-differentiated portions: a first large chamber containing ridges and a smooth portion (Icardo et al., 2010; Rafn \& Wingstrand, 1981). This could be due to the difference in age of the fish used in the respective studies. The early age of the larvae could explain the absence of the ridges in the anterior spiral intestine at 17 $\mathrm{DPH}$, unlike the anterior spiral intestine in juvenile $P$. annectens of $100 \mathrm{~g}$ to $150 \mathrm{~g}$. As in juvenile West African lungfish, the mucosa had a lamina propria which was very rich in collagen. It also contained the vasculature that supplied the epithelium (Icardo et al., 2011).

The spiral valve intestine had several types of cells; enterocytes are the dominant type of cells at $17 \mathrm{DPH}$ and constitute a major component of the epithelium just as in juveniles of both the Australian and West African lungfishes (Icardo et al., 2011; Rafn \& Wingstrand, 1981). The enterocytes play both absorptive and secretory functions in mammals (Ross, Kaye, \& Pawlina, 2003). However, functionality was not investigated in our study and such studies will be very important to understand the role played by these cells in marbled African lungfish larvae. Goblet cells are common components of the digestive mucosa of larvae and adult fish (Zambonino Infante et al., 2008). In different vertebrates including fish, these cells are involved in transport, absorption and protection processes of the gut (Zambonino Infante et al., 2008). In fish, mucosubstances produced by buccopharyngeal and oesophageal goblet cells play an important lubricant role due to the lack of salivary glands, protecting the digestive mucosa from abrasion that feed particles may produce (Scocco, Accili, Menghi, \& Ceccarelli, 1998; Zambonino Infante et al., 2008). The presence of goblet cells at 17 DPH may be an indication of absorptive preparedness in the lower digestive tract. This was also found in African catfish larvae by $3 \mathrm{DPH}$ (Onura et al., 2018). Mucosubstances produced by goblet cells located in the cloaca may serve to lubricate the faeces, and in the intestine, they facilitate the absorption of nutrients as in other fish species 
(Zambonino Infante et al., 2008). Other cell types found present in the connective tissue were pigment cells. They traverse both the connective and epithelial tissue just as shown in the juvenile $P$. annectens (Icardo et al., 2011). The significance of these pigment cells in lungfish larvae is unclear, and our study did not investigate the role of the different cell types.

By $17 \mathrm{DPH}$, lungfish larvae had a well-differentiated mouth with structures for capturing and tasting preys, a developed vestibule and intestinal mucosa and a differentiated accessory digestive gland for nutrient storage (liver). At this stage, histological data indicated that the digestive system was functional and able to digest food, as first signs of lipid accumulation in the liver were noticed at the same time goblet cells were also seen in the gastrointestinal tract. Gisbert et al. (2014) highlighted lipid accumulation in the anterior and intermediate regions of the intestine and liver together with the onset of exogenous feeding in Pseudoplatystoma punctifer, an Amazonian pimelodid catfish, at 4 days post-fertilization at a time when the larvae were ready to receive exogenous feeding. The introduction of a cofeeding period for African lungfish larvae would be advantageous as it would guarantee a successful transition to exogenous feeding and minimize the negative effects of missing the narrow first-feeding window.

In conclusion, the ontogeny of the digestive system of P. aethiopicus followed the same general pattern as most teleost species described to date. Studies on the structure and function of the digestive system in marbled African lungfish larvae will lead to a better understanding of the digestive physiology of this high-value species. These results on the organogenesis of larvae are a useful tool for establishing the functional capabilities and physiological requirements of larvae to ensure optimal welfare and growth under aquaculture conditions. This is a first contribution to master the larval rearing of the African lungfish. Future research should be focused on the ontogeny of enzymatic secretions to provide precise information about the functionality of the digestive tract. It should also evaluate the effect of different feeding regimes using live feeds and/or formulated diets, on the maturation of the digestive tract.

\section{ACKNOWLEDGMENT}

The authors wish to thank the following people and organizations: Dr Rukunya. E., Directorate of Fisheries Resources, Ministry of Agriculture, Animal Industry and Fisheries, Entebbe, Uganda for granting us permission to collect and use wild fish eggs; the Head of the Aquaculture Research and Development Centre- Kajjansi, who availed culture facilities for our research activity; Bart De Pauw and Lobke De Bels, Department of Morphology, Faculty of Veterinary Medicine, Ghent University, Belgium, for their technical support in the histological analysis. Financial support for this work was provided through the Flemish Interuniversity Council VLIRUOS, programme ZIUS, 2013-2024, AP027, under the Institutional Cooperation with Mountains of the Moon University (MMU), Fort Portal, Uganda Programme.

\section{CONFLICTS OF INTEREST}

The authors declare no conflict of interest.

\section{AUTHORS CONTRIBUTIONS}

Martin Sserwadda contributed ideas to conception and experimental design and was involved in slide generation and microscopic analysis, drafting and revision of the manuscript. Ronald Ntanzi contributed to slide generation and microscopic analysis. Nancy Nevejan: contributed ideas to conception and experimental design and was critically involved in revising the manuscript and funding. Pieter Cornillie contributed ideas and design of the 3D reconstruction and was critically involved in manuscript revision for important intellectual content. Wim Van den Broeck contributed ideas for histological and microscopic analysis and was critically involved in manuscript revision for important intellectual content. Gilbert Van Stappen involved in ideas, was critically involved in manuscript revision for important intellectual content and gave the final approval of the version to be published.

\section{DATA AVAILABILITY STATEMENT}

The data that support the findings of this study are available from the corresponding author upon reasonable request.

\section{ORCID}

Martin Sserwadda iD https://orcid.org/0000-0002-4212-6803

\section{REFERENCES}

Buddington, R. K. (1985). Digestive secretions of lake sturgeon (Acipenser fulvescens) during early development. Journal of Fish Biology, 26, 715723. https://doi.org/10.1111/fsbi.1095-8649

Cornillie, P., Van Den Broeck, W., \& Simoens, P. (2008). Three-dimensional reconstruction of the remodelling of the systemic vasculature in early pig embryos. Microscopy Research and Technique, 71, 105-111. https://doi.org/10.1002/jemt.20531

Fischer, A. H., Jacobson, K. A., Rose, J., \& Zeller, R. (2008). Hematoxylin and eosin staining of tissue and cell sections. Cold Spring Harbor Protocols, 5, 4986. https://doi.org/10.1101/pdb.prot073411

German, P. D., Neuberger, T. D., Callahan, N. M., Lizardo, R. N., \& Evans, H. D. (2009). Feast to famine: The effects of food quality and quantity on the gut structure and function of a detritivorous catfish (Teleostei: Loricariidae). Journal of Comparative Biochemistry and Physiology, Part A., 155(3), 281-293. https://doi.org/10.1016/j.cbpa.10.018

Gisbert, E., Conklin, D. B., \& Piedrahita, R. H. (2004). Effects of delayed first feeding on the nutritional condition and mortality of California halibut larvae. Journal of Fish Biology, 64(1), 116-132. https://doi. org/10.1111/jfsbi.1095-8649.00289.x

Gisbert, E., Morais, S., \& Moyano, F. J. (2013). Feeding and digestion. In J. G. Kim (Ed.), Larval fish aquaculture (pp. 73-123). New York, NY: Nova Publishers.

Gisbert, E., Moreira, C., Castro-Ruiz, D., Öztürk, S., Fernández, C., Gilles, S., \& Darias, M. J. (2014). Histological development of the digestive system of the Amazonian pimelodid catfish Pseudoplatystoma punctifer. Animal, 8(11), 1765-1776. https://doi.org/10.1017/S175173111 4001797

Gisbert, E., Ortiz-Delgado, J. B., \& Sarasquete, C. (2008). Nutritional cellular biomarkers in early life stages of fish. Histology and Histopathology, 23(12), 1525-1539.

Gisbert, E., Sarasquete, M. C., Williot, P., \& Castelló, F. (1999). Histochemistry of the development of the digestive system of Siberian sturgeon (Acipenser baeri, Brandt) during early ontogeny. Journal of Fish Biology, 55, 596-616. https://doi.org/10.1111/j.1095-8649.tb00702.x

Govoni, J. J., Boehlert, G. W., \& Watanabe, Y. (1986). The physiology of digestion in fish larvae. Environmental Biology of Fishes, 16(1-3), 59-77. 
Grosell, M., Farrell, A. P., \& Brauner, C. J. (2010). Fish physiology: The multifunctional gut of fish. London, UK; Academic Press London, 30, 1-448.

Gurcan, M. N., Boucheron, L. E., Can, A., Madabhushi, A., Rajpoot, N. M., \& Yener, B. (2009). Histopathological image analysis: A review. IEEE Reviews in Biomedical Engineering, 2, 147-171. https://doi. org/10.1109/RBME.2034865

Holmgren, S., \& Nilsson, S. (1999). Digestive system. In W. C. Hamlett (Eds.), Sharks, skates and rays, the biology of elasmobranch fishes (pp. 144-172). Baltimore, MD: The John Hopkins University Press.

Icardo, J. M., Wong, W. P., Colvee, E., Garofalo, F., Loong, A. M., \& Yuen, K. I. (2011). The gut of the juvenile African lungfish Protopterus annectens: A light and scanning electron microscope study. Journal of Morphology, 272, 769-779. https://doi.org/10.1002/jmor.10952

Icardo, J. M., Wong, W. P., Colvee, E., Loong, A. M., \& Yuen, K. I. (2010). The anatomy of the gastrointestinal tract of the African lungfish, Protopterus annectens. The Anatomical Record, 293, 1146-1154. https://doi.org/10.1002/ar.21154

Jaroszewska, M., \& Dabrowski, K. (2011). Utilization of yolk: Transition from endogenous to exogenous nutrition in fish. In G. J. Holt (Eds.), Larval fish nutrition (pp. 183-218). Chichester, UK: John Wiley \& Sons Inc.

Joss, J., \& Hassanpour, M. (2009). Anatomy and histology of the spiral valve intestine in juvenile Australian lungfish, Neoceratodus forsteri. The Open Zoology Journal, 2, 62-85.

Kamisaka, Y., \& Rønnestad, I. (2011). Reconstructed 3D models of digestive organs of developing Atlantic cod (Gadus morhua) larvae. Marine Biology, 158, 233-243.

Kardong, K. V. (2006). Vertebrates: Comparative anatomy, function, evolution, (4th ed.). New York, Ny: McGraw-Hill.

Khojasteh, S. M. B. (2012). The morphology of the post-gastric alimentary canal in teleost fishes: A brief review. International Journal of Aquatic Science, 3(2), 71-88.

Mlewa, C. M., Green, J. M., \& Dunbrack, R. L. (2010). The general history of the African Lungfishes. In J. M. Jørgensen, \& J. Joss (Eds.), The Biology of Lungfishes (pp. 97-127). Boca Raton, Fl: Taylor \& Francis Group, CRC Press.

Onura, N. C., Wim, V. D. B., Nevejan, N., Muendo, P., \& Gilbert, V. S. (2018). Growth performance and intestinal morphology of African catfish (Clarias gariepinus, Burchell, 1822) larvae fed on live and dry feeds. Aquaculture, 489, 70-79. https://doi.org/10.1016/j.aquac ulture.01.046

Osman, A. G. M., Wuertz, S., Mekkawy, I. A., Verreth, J., \& Kirschbaum, F. (2008). Early development of the African catfish Clarias gariepinus (Burchell, 1822), focusing on the ontogeny of selected organs. Journal of Applied Ichthyology, 24(2), 187-195. https://doi. org/10.1111/j.1439-0426.01018x

Ostaszewska, T. (2005). Developmental changes of digestive system structures in pike-perch (Sander lucioperca L.). Electronic Journal of Ichthyology, 2, 65-78.

Pradhan, P. K., Jena, J. K., Mitra, G., Sood, N., \& Gisbert, E. (2012). Ontogeny of the digestive tract in butter catfish Ompok bimaculatus (Bloch) larvae. Fish Physiology and Biochemistry, 38, 1601-1617. https://doi.org/10.1007/s10695-012-9655-8

Rafn, S., \& Wingstrand, K. G. (1981). Structure of intestine, pancreas, and spleen of the Australian Lungfish, Neoceratodus forsteri (Krefft). Zoologica Scripta, 10, 223-239. https://doi.org/10.1111/j.1463-6409. tb00498x
Rønnestad,I.,Yúfera, M.,Ueberschär, B., Ribeiro,L., Sæle,Ø., \&Boglione,C. (2013). Feeding behaviour and digestive physiology in larval fish: Current knowledge, and gaps and bottlenecks in research. Reviews in Aquaculture, 5(1), 59-69. https://doi.org/10.1111/raq.12010

Ross, M. H., \& Pawlina, W. (2003). Histology. A Text and Atlas: With Correlated Cell and Molecular Biology, (4th ed.). Baltimore, MD: Lippincott Williams \& Wilkins.

Santos, A. E., Pedreira, M. M., Santos, T. G., \& Souza, G. D. (2016). Development of the digestive system in larvae of the Neotropical fish Prochilodus argenteus (Characiformes, Prochilodontidae). Animal Sciences, 36(1), 9-16.

Sarasquete, C., Gisbert, E., Ribeiro, L., \& Dinis, M. T. (2001). Glycoconjugates in epidermal, branchial and digestive mucous cells and gastric glands of gilthead sea bream, Sparus aurata, Senegal sole, Solea senegalensis and Siberian sturgeon, Acipenser baeri development. European Journal of Histochemistry, 45, 267-278. https://doi. org/10.4081/1637

Scocco, P., Accili, D., Menghi, G., \& Ceccarelli, P. (1998). Unusual glycoconjugates in the oesophagus of a tilapine poly hybrid. Journal of Fish Biology, 53, 39-48. https://doi.org/10.1111/j.1095-8649.tb00107.x

Treveriño, L., Alvarez-González, C. A., Arévalo-Galán, L., UscangaMartÍnez, A., Márquez-Couturier, G., Fernández, I., \& Gisbert, E. (2011). A histological study of the organogenesis of the digestive system in bay snook Petenia splendida Günther, 1862 from hatching to the juvenile stage. Journal of Applied Ichthyology, 27(1), 73-82. https://doi.org/10.1111/j.1439-0426.01608.x

Verreth, J. A., Torrelle, E., Spazier, E., \& Sluiszen, H. W. (1992). The development of a functional digestive system in the African catfish, Clarias gariepinus. Journal of World Aquaculture Society, 23, 286-298. https://doi.org/10.1111/j.1749-7345.tb00792.x

Walakira, J. K., Atukunda, G., Molnar, J. J., \& Veverica, K. L. (2012). Prospects and potential for aquaculture of African Lungfish in Uganda. World Aquaculture, 43(3), 38-42.

Walakira, J. K., Molnar, J. J., Phelps, R., \& Terhune, J. (2014). Culturing the African lungfish in Uganda: Effects of exogenous fish feed on growth performance in tanks. Uganda Journal of Agricultural Sciences, 15(2), 137-155.

Wilson, J. M., \& Castro, L. F. C. (2010). Morphological diversity of the gastrointestinal tract in fishes. Fish Physiology, 30, 1-55. https://doi. org/10.1016/S1546-5098(10)3001-3

Zambonino Infante, J. L., Gisbert, E., Sarasquete, C., Navarro, I. G., Gutiérrez, J., \& Cahu, C. L. (2008). Ontogeny and physiology of the digestive system of marine fish larvae. In J. E. P. Cyrino, D. P. Bureau, \& B. G. Kapoor (Eds.), Feeding and digestive functions of fishes (pp. 277-344). Enfield, NH; Cyrino, Science Publishers Inc.

How to cite this article: Sserwadda M, Nevejan N, Ntanzi R, Cornillie P, Van den Broeck W, Van Stappen G. Ontogenetic development of the gastrointestinal tract of African lungfish larvae Protopterus aethiopicus (Heckel 1851): A light microscopy study. Aquac Res. 2020;51:5074-5083. https://doi. org/10.1111/are.14846 